Rev. Interd. em Cult. e Soc. (RICS), São Luís, v. 6, n. 2, p. 227-247, jul./dez. 2020

ISSN eletrônico: $2447-6498$

\title{
Fatores de Antropização no Isolamento e Distanciamento Sociais durante a Pandemia DE COVID-19: estudo de caso em cidade local da amazônia estuarina $^{1}$
}

\section{Anthropization factors in social isolation and distancing during the Covid- 19 Pandemic: case study in a local city of estuarian amazon}

JOSÉ GUILHERME DOS SANTOS FERNANDES Professor Associado e Pesquisador do PPG em Estudos Antrópicos na Amazônia (PPGEAA/UFPA); Doutor em Letras (UFPB); Pós-Doutorado UNTREF (Argentina, 2014). guilherme.profufpa@gmail.com

MARCOS CÉSAR DA ROCHA SERUFFO Professor Adjunto (UFPA); Professor Adjunto e Pesquisador do PPG em Estudos Antrópicos na Amazônia (PPGEAA/UFPA); Doutor em Engenharia Elétrica/Computação Aplicada (UFPA). marcos.seruffo@gmail.com

RONDINELL AQUINO PALHA Mestrando do PPG em Estudos Antrópicos na Amazônia (PPGEAA/UFPA); Membro do Colaboratório de Interculturalidades, Inserção de Saberes e Inovação Social (COLINS). rondipalha@gmail.com

RENATA DE CÁSSIA SILVA SALES Graduada em Ciências Contábeis (2014); Membro do Colaboratório de Interculturalidades, Inserção de Saberes e Inovação Social (COLINS). renatacssales@gmail.com

SUZANNE ALBUQUERQUE DOS SANTOS Graduanda de Letras (NUSC/UFPA); Membro do Colaboratório de Interculturalidades, Inserção de Saberes e Inovação Social (COLINS). suzanne26santos@gmail.com

\section{RESUMO}

Considerando a pandemia atual, este artigo aborda fatores de antropização que auxiliem indicadores de distanciamento social considerando realidades próprias da região amazônica. Foi conduzida a aplicação de formulário com moradores da cidade de São Caetano de Odivelas - Pará, localizada na zona estuarina do rio Amazonas, quanto à concordância, discordância ou indiferença por decorrência de determinações governamentais e de saúde pública. Observou-se que há dificuldade em relacionar demandas locais com as nacionais e globais, acarretando em comportamentos que podem comprometer a eficiência do isolamento social, assim, são propostos indicadores para distanciamento social.

\footnotetext{
${ }^{1}$ Artigo submetido para avaliação em 13/07/2020 e aprovado em 20/ 10/2020.
} 
Palavras-chave: Indicadores. Coronavírus. Antropização. Isolamento Social. Distanciamento Social. Cidade Local.

\begin{abstract}
Considering the current pandemic, this article addresses anthropization factors that help social distancing indicators focused on realities specific to the Amazon region. A form was applied to residents of the city of São Caetano de Odivelas - Pará, located in the estuarine zone of the Amazon River, regarding agreement, disagreement or indifference due to government and public health determinations. It was observed that there is difficulty in relating local demands with national and global ones, resulting in behaviors that can compromise the efficiency of social isolation, thus, indicators for social distance are proposed.
\end{abstract}

Keywords: Indicators. Coronavirus. Anthropization, Social Isolation. Social Distancing. Local City

\title{
1. INTRODUÇÃO
}

A utilização de elementos quantitativos, dentre estes dados censitários, para tomada de decisão em políticas públicas é amplamente utilizada. No Brasil, o Instituto Brasileiro de Geografia e Estatística (IBGE) nasceu com a premissa de retratar o país a partir de informações necessárias ao conhecimento de sua realidade e ao exercício da cidadania, constituindo-se no principal provedor de dados e informações demográficas e sociais, que atendem às necessidades dos mais diversos segmentos da sociedade civil, bem como dos órgãos das esferas governamentais federal, estadual e municipal (IBGE, 2020). Os indicadores são instrumentos para obtenção de informações sobre dada realidade, individual ou agregado de informações, a partir da presença de variáveis e representação operacional de um atributo de um sistema. O indicador pode gerar um índice, que revela o estado de um sistema ou fenômeno, além do valor agregado de um procedimento de cálculo e a transformação de um conceito em uma medida.

Mas se por um lado os indicadores criam as condições para retratar a totalidade da sociedade, como em uma nação, de outro modo podem limitar esse recorte ao não considerarem as particularidades do fenômeno conforme a ocorrência deste em realidade particular, como no caso de regiões e territórios com história e práticas culturais marcantes e indenitárias em relação ao país, caso da Amazônia, uma região cultural que se configura desde um bioma distinto do restante do Brasil, o que nos faz mais próximos da realidade de Iquitos, no Perú, do que irmanados com as práticas e valores culturais dos caiçaras paulistanos ou gaúchos dos pampas. Por isso, sem descartar a necessidade precípua de indicadores amplos nacionais, aqui advogamos também pela necessidade de recortes mais específicos, considerando-se a opinião dos "nativos", pois esta questão é ainda mais latente quando se concebe que esta opinião advém de fatores que concorrem para sua antropização, entendida como 
[...] toda e qualquer ação humana, ou resultado desta, no meio "natural", seja de ordem comportamental ou ambiental, produzindo modificações construtivas ou destrutivas; neste particular, o conceito deve ser utilizado de forma relacional, pois o sentido de valoração destas modificações é dependente dos grupos transformadores e que estão em contato mediante o uso partilhado do ambiente transformado, pois uma ação positiva para um grupo pode ser negativa para outro que utiliza o mesmo território, o que pode afetar deveras a territorialidade de cada grupo e, consequentemente, afetar as relações hierárquicas entre eles e a condição hegemônica territorial (FERNANDES; FERNANDES, 2018, p.89).

Este conceito pode nos dar luz sobre a questão do isolamento social quando observado a partir da declaração da Organização Mundial de Saúde (OMS) sobre a pandemia do Covid19, doença causada pelo novo coronavírus - Sars-Cov-2 (OPAS, 2020). Contudo, em situações excepcionais, as infecções causadas por qualquer um dos coronavírus humanos podem evoluir para casos mais graves, especialmente em idosos, crianças e pessoas imunodeprimidas. Na última década, no entanto, dois novos vírus surgiram como agentes infecciosos muito perigosos para os humanos, conhecidos como: SARS-CoV (Síndrome respiratória aguda grave), e o MERS-CoV (Síndrome respiratória do oriente médio causada por coronavírus). Os coronavírus (CoV) englobam um grupo de vírus, que podem causar problemas respiratórios sem grande gravidade Andersen et al. (2020).

Nota-se diferentes indicadores sendo tratados a partir do alastramento do vírus pelo Mundo, especificamente pelo Brasil. O novo coronavírus SARS-CoV-2 que causa a doença COVID-19 se propaga principalmente de pessoa para pessoa e também pelo contato com superfícies contaminadas Yan et al. (2020). Há pesquisas que retratam curvas associadas aos novos casos da doença (WANG ET AL, 2020), pesquisas associadas ao número de leitos disponíveis $^{23}$, pesquisas que levam em consideração o número de mortos (Wang et al. 2020), pesquisadas que utilizam a quantidade de recuperados (Wang et al. 2020), controle de movimentação nas ruas a partir de registros de antenas de telefones móveis (JN, 2020) e uso de redes sociais para aprender como organizar as postagens relacionadas ao COVID-19 (LI ET AL, 2020).

Entretanto, uma questão é amplamente aceitável até o momento, em que inexiste vacina específica e um tratamento protocolar amplamente aceito pelos países: para evitar-se o aumento expressivo de casos de Covid-19, e com isso o estrangulamento e falência do sistema de saúde dos países, há necessidade de conter os movimentos humanos, sejam os

\footnotetext{
${ }^{2}$ https://covid-calc.org

${ }^{3}$ https://covid.mapbiomas.org
} 
internacionais, como viagens de turismo e negócios, sejam os nacionais, como os deslocamentos diários para o consumo ou o trabalho, como ocorre nas cidades e entre estas. Em uma palavra, deve-se praticar o isolamento social, que é o apanágio deste trabalho de pesquisa. Entende-se aqui como isolamento social o recolhimento expresso do indivíduo, e de sua família, em convivência cotidiana restrita ao ambiente doméstico de sua residência, com contatos mínimos e extremamente necessários com o ambiente e os indivíduos externos a esta, unicamente para garantir-se a sua sobrevivência e a de seus próximos, com finalidades alimentares e de saúde.

É certo que pesquisadores vêm se empenhado para entender o comportamento da doença e seu respectivo alastramento exponencial, o que é um fenômeno de ordem mundial, pois a busca por estruturas virais e a sistemática biológica de transmissão afeta o ser humano como um todo. Mas o processo não é trivial, apesar de haver sintonia nas formas de prevenção, pois há ampla discussão sobre quais medidas devem ser tomadas para que a doença não avance; neste aspecto, diversos países adotaram como medida principal o isolamento social e essas medidas obtêm sucesso ou não conforme as práticas e valores culturais de cada sociedade e país.

No Brasil não foi diferente, apesar de haver contrapontos sobre a medida, o isolamento está sendo adotado por grande parte da população, alguns estudos, inclusive, tentam prever em outros países o que se esperar a partir dos níveis de isolamento (GUGLIELMO, 2020). O que deve ser discutido (geralmente negligenciado por estudos de medidas de isolamento social) é quais indicadores podem/devem ser utilizados para que o processo de relaxamento do isolamento social ocorra, em conformidade com as práticas e valores culturais de populações específicas, como os povos e comunidades tradicionais da Amazônia, pois mesmo o isolamento, como ação extremamente restritiva do direito de ir-e-vir, atenta deveras contra uma prática enraizada nessas comunidades, em que as relações parentais e de compadrio, além da convivencialidade entre os indivíduos, são frequentes, em contatos diários e interlocutivos diretos, através de conversas, visitas, circulação entre moradias de parentes e vizinhos, bem como em encontros nas ruas e nas filas nos espaços de comércio das cidades locais na Amazônia; o contato direto e cotidiano entre as pessoas "conhecidas" é uma verdadeira instituição social que conforma e estrutura as relações antrópicas naqueles espaços.

Considerando-se o exposto, este artigo aborda aspectos antrópicos (particularidades locais da relação humano e ambiente) que diferenciam a tomada de decisão sobre políticas para o isolamento social. O intuito é gerar uma discussão que leve em consideração não somente questões unicamente quantitativas para essa tomada de decisão, dada a 
Rev. Interd. em Cult. e Soc. (RICS), São Luís, v. 6, n. 2, p. 227-247, jul./dez. 2020

ISSN eletrônico: $2447-6498$

continentalidade do Brasil. Decorrente desta consideração, surge a hipótese de que na realidade brasileira nem sempre as políticas públicas, neste momento relacionadas ao isolamento social, são bem-sucedidas em função de não haver consideração de particularidades locais e regionais. Para discussão desta hipótese, apresenta-se um estudo de caso na cidade de São Caetano de Odivelas, localizada no Estado do Pará, na região do estuário do rio Amazonas, configurando-se em espaço de produção pesqueira e de práticas comunitárias de caráter tradicional, daí serem diferenciados os valores em relação ao que se pode considerar os princípios de uma sociedade de caráter nacional, por mais que se observem os preceitos desta, ainda mais em demandas emitidas por um governo estatal, que é o caso neste momento de pandemia por Covid-19.

\section{REFERENCIAL TEÓRICO}

Para se entender a visão diferenciada na relação entre o local e o nacional/global, e com isso compreender a legitimidade ou não de políticas de estado, que possam afetar os espaços comunitários tradicionais, em determinados grupos sociais do país, precisa-se ter em conta que o estado-nacional se configura por sua autoridade e monopólio para estabelecer e aplicar leis e ordens coletivamente, pois

O Estado é organizado em torno de um conjunto de funções sociais, incluindo manter a lei, a ordem e a estabilidade, resolver vários tipos de litígios através do sistema judiciário, encarregar-se da defesa comum e cuidar do bem-estar da população de maneiras que estão além dos meios do indivíduo, tal como implementar medidas de saúde pública, prover educação de massa e financiar pesquisa médica dispendiosa (JOHNSON, 1997, p. 91).

É o caso deste ano de 2020, em que o estado brasileiro necessita implementar medidas de saúde pública para a minimização da transmissão de coronavírus, o que nem sempre é bem-sucedido em razão de que o estado deve ter um viés de nação, pois quando há um estadonacional se entende que o povo (enquanto coletivo que vive em dado território) se identifica com o seu governo, por extensão obedece às leis do estado-nacional. Em um país continental como o Brasil deve haver um amplo reconhecimento e um esforço do estado brasileiro em se fazer reconhecido pelo seu povo para que as ordens emanadas do poder central sejam irremediavelmente obedecidas. E para isso é necessário que o estado represente seu povo, com sua diversidade de valores e de práticas culturais, e é exatamente disso que queremos tratar nesta ocasião, mediante possibilidades de fatores antrópicos, particularmente de população amazônica, a serem considerados quando do isolamento social pela pandemia. 
Em cidades locais, a exemplo de São Caetano de Odivelas, cidade foco de nossa pesquisa, em que há grande convivência comunitária, deve-se atentar que mesmo que haja um conjunto de serviços de atenção à população, próprios da modernidade urbana, como serviços bancários, lojas diversas, supermercados e mercearias, lojas de produtos agrícolas, serviços públicos municipais e estaduais, escolas de educação básica e de cursos superiores, ocorre, de outro modo, como atividade polarizante, a pesca, o que classifica a cidade como de subsistência, com acentuada prática laboral vinculada à comunidade tradicional, em que as relações de proximidade entre os indivíduos (relações de parentesco e compadrio), próprias destas estruturas sociais, criam resistência à aceitação irrestrita de determinações externas e oriundas de um poder estatal, que não participa rotineiramente da realidade local, bem como a população situa essas determinações em realidade bem distante, e quase estranha ao seu meio imediato.

Para Santos (2008, p.87) o que caracteriza uma cidade local é “[...] uma atividade polarizante e, dadas as funções que elas exercem em primeiro nível, poderíamos quase falar de cidades de subsistência". É o caso de São Caetano de Odivelas, por sua atividade extrativa de pesca, o que a caracteriza como uma sociedade tradicional, visto que Diegues (2002) assim compreende as culturas e sociedades tradicionais: dependência dos ciclos naturais, conhecimento aprofundado da natureza, noção de território ou espaço, importância das atividades de subsistência. Vinculado às práticas de proximidade e dependência com o ambiente, aparecem os valores assentados nas relações de proximidade entre os indivíduos:

“d) moradia e ocupação desse território por várias gerações $(. .$.$) ; g) importância dada à$ unidade familiar, doméstica ou comunal e às relações de parentesco ou compadrio (...); 1) auto-identificação ou identificação pelos outros de se pertencer a uma cultura distinta das outras" (DIEGUES, 2002, p.89).

Em razão dessa particularidade de comunidades locais e tradicionais, em relação ao estado nacional brasileiro, entendemos, a partir da pesquisa realizada, que se deve focar, por ocasião de regras para o isolamento social, as relações antrópicas de cada grupo em particular. Pois que é necessário pensar a antropização como

[...] a interação entre grupos distintos que utilizam o mesmo território e que são atingidos diretamente por transformações mútuas que afetam os saberes ambientais, ideologias e identidades - coletivamente criados e historicamente situados -, que cada grupo social utiliza para estabelecer e manter este território comum, em regime de propriedade, vínculos afetivos, história de ocupação na memória coletiva, uso social e formas de defesa (FERNANDES \& FERNANDES, 2018, p.89). 
Rev. Interd. em Cult. e Soc. (RICS), São Luís, v. 6, n. 2, p. 227-247, jul./dez. 2020

ISSN eletrônico: 2447-6498

Fica então a proposição de que os grupos atingidos pela Pandemia - aqui entenda-se o grupo local, ou a comunidade odivelense, e o grupo nacional, ou o regramento de Estado sejam postos em correlação por serem usuários do mesmo território, o município de São Caetano de Odivelas, que é o território brasileiro, evidentemente, e por isso os efeitos da Covid-19 afetam os dois grupos, de alguma maneira. Entendemos que esse panorama apresentado, acerca das relações entre o local e o nacional, objetiva-se no caráter do isolamento social, enquanto um conceito a ser problematizado. Porque a Lei $\mathrm{n}^{\circ} 13.979$, de 6 de fevereiro de 2020, que dispõe sobre as medidas para enfrentamento da emergência de saúde pública de importância internacional decorrente do Coronavírus, considera, em seu Art. $2^{\circ}$, o seguinte:

I - isolamento: separação de pessoas doentes ou contaminadas, ou de bagagens, meios de transporte, mercadorias ou encomendas postais afetadas, de outros, de maneira a evitar a contaminação ou a propagação do coronavírus; e

II - quarentena: restrição de atividades ou separação de pessoas suspeitas de contaminação das pessoas que não estejam doentes, ou de bagagens, contêineres, animais, meios de transporte ou mercadorias suspeitos de contaminação, de maneira a evitar a possível contaminação ou a propagação do coronavírus (BRASIL, Lei 13.979/2020, I-II).

Por outro lado, do ponto de vista científico, compreende-se, primeiramente, que o isolamento social pode ser voluntário - por razões de vontade própria ou de ordem religiosa, ou ainda por afecções psiquiátricas - ou involuntário - decorrente de guerras, conflitos sociais ou epidemias/pandemias. Neste último caso, relacionado a fins sanitários, o isolamento significa:

[...] medida que visa separar as pessoas doentes (sintomáticos respiratórios, casos suspeitos ou confirmados de infecção por coronavírus) das não doentes, para evitar a propagação do vírus. O isolamento pode ocorrer em domicílio ou em ambiente hospitalar, conforme o estado clínico da pessoa. Essa ação pode ser prescrita por médico ou agente de vigilância epidemiológica e tem prazo máximo de 14 dias. Na prescrição do isolamento o paciente deve assinar um termo de consentimento livre e esclarecido e seguir as orientações para evitar o contágio de seus contatos domiciliares (UFRGS/TELESSAÚDE 2020, p.1).

O que se deve compreender é que no uso corrente, nesta atualidade da Pandemia em 2020, no Brasil, a visão marcadamente médica e científica, de se vincular o isolamento como “separação de pessoas doentes e contaminadas", não tem se aplicado, mesmo porque, ainda neste momento, maio de 2020, é impossível a ampla testagem da população para a confirmação de infecção por coronavírus, pois a avassaladora procura por insumos para tanto, 
e a restrita fabricação de testes por alguns países, fez com que o governo brasileiro declarasse a incompetência para realização de testagem em massa. Por isso não se saber quem efetivamente está doente ou não; considera-se a possibilidade da doença apenas pela sintomatologia clínica, em efeitos de febre, coriza, inflamação nas vias aéreas, diminuição de olfato e paladar e ainda dificuldade respiratória.

Assim, o uso do termo isolamento social teve que ser adequado à realidade, para efeitos desta pesquisa significando a restrição à convivência cotidiana do indivíduo e de sua família ao ambiente doméstico de sua residência, com contatos mínimos e extremamente necessários com o ambiente e os indivíduos externos a esta, estritamente para garantir-se a sua sobrevivência e a de seus próximos, sem obrigatoriamente estar vinculado à separação e pessoas doentes ou contaminadas. E este foi o conceito esclarecido aos participantes por ocasião da aplicação dos formulários de pesquisa em campo.

Até compreendemos que talvez o conceito mais apropriado fosse o de quarentena, que significa

[...] a restrição de atividades ou separação de pessoas que foram presumivelmente expostas a uma doença contagiosa, mas que não estão doentes (porque não foram infectadas ou porque estão no período de incubação). A quarentena pode ser aplicada em nível individual (...) ou em nível coletivo (...). Pode ser voluntária ou mandatória (UFRGS/Telessaúde, 2020, p.1).

Esta concepção aponta mais claramente para seu uso em relação a públicos nãodoentes, mesmo que potencialmente expostos, que foi o caso dos pesquisados. Mas a Portaria $n^{\circ} 356 / 2020$ - MS, que regulamenta a referida Lei, em seu Art. $4^{\circ}, \S 2^{\circ}$, discrimina que o prazo para a medida será de até 40 (quarenta) dias, mesmo que haja a possibilidade de extensão deste prazo, mas com prévia autorização do Ministério da Saúde. Para a situação atual de que não há prazos realmente exequíveis de restrição, pois que não existe vacina ou mesmo protocolo mundial acordado para o tratamento, determinar-se aprazamentos para o isolamento social, na perspectiva de uma quarentena, é temeroso, pois que os cientistas ainda correm para desenvolverem processos de cura, sem prazos fechados para soluções imediatas.

Outro conceito apropriado para uso, nesta pesquisa, é o de distanciamento social, como

[...] a diminuição de interação entre as pessoas de uma comunidade para diminuir a velocidade de transmissão do vírus. É uma estratégia importante quando há indivíduos já infectados, mas ainda assintomáticos ou 
Rev. Interd. em Cult. e Soc. (RICS), São Luís, v. 6, n. 2, p. 227-247, jul./dez. 2020

ISSN eletrônico: $2447-6498$

oligossintomáticos, que não se sabem portadores da doença e não estão em isolamento (UFRGS/TELESSAÚDE, 2020, p1).

O distanciamento social é um conceito importante para o relaxamento ${ }^{4}$ do isolamento social e para esta pesquisar por implicar na convivência mais frequente entre o indivíduo e sua família com o ambiente e os indivíduos fora do espaço doméstico, em certa regularidade de contatos, mas com ressalvas ao contato direto, que poderá ocorrer presencialmente desde que mantida distância de segurança para evitar-se contágios, além da atenção aos protocolos de uso de Equipamento de Proteção Individual (EPI) e de medidas assépticas por parte dos interlocutores, durante e após os contatos.

Em todo caso, somente com a tomada de opinião entendemos ser possível o estabelecimento de diretrizes para isolamento ou relaxamento desta iniciativa, uma vez que os indicadores oriundos destas diretrizes devem contribuir para identificar e medir um fenômeno, considerando-se nestes a validade (adequação para medir o fenômeno), a confiabilidade (fidedignidade ao evento) e a representatividade (cobertura alcançada do evento). Pois do contrário,

[...] as práticas de mensuração da influência das atividades humanas sobre o meio têm se apresentado controversas e raramente conseguem realizar ligações diretas entre as causas geradoras das demandas psicológicas individuais, socioeconômicas e culturais, e suas consequências ambientais (BOLLMANN, 2001, p.15).

Este trabalho de pesquisa tem o intuito de tratar, de forma inicial, dessas causas geradoras. $\mathrm{O}$ intuito é determinar diretrizes para o conjunto de indicadores de isolamento e distanciamento sociais, que se configurem a partir de realidades próprias da região amazônica.

\section{Metodologia da Pesquisa}

A pesquisa é de caráter quanti-qualitativo, pois parte da coleta de informações e tratamento analítico de dados a partir de grupo de informantes determinado pelo recorte quantitativo, mas, complementarmente, realizamos a análise e interpretação baseadas na opinião (subjetividade) dos sujeitos, em indissociabilidade representativa destes quanto ao universo pretendido, a cidade de São Caetano de Odivelas. Por isso também nosso método se enquadra como indutivo, pois a partir das condições particulares opinativas pretendeu-se a generalização construída com a observação do fenômeno.

\footnotetext{
${ }^{4}$ Neste caso, o termo refere-se ao retorno gradativo das atividades cotidianas.
} 
A coleta foi realizada no período de 6 a 10 de abril de 2020, com 20 moradores em razão de ser considerada cidade local (SANTOS, 2008), abrigar um núcleo de ensino e pesquisa da Universidade Federal do Pará (UFPA), com um curso de graduação em Letras, e ainda ser campo de investigações do Programa de Pós-Graduação em Estudos Antrópicos na Amazônia (PPGEAA/UFPA), ao qual se vincula o Colaboratório de Interculturalidades, Inserção de Saberes e Inovação Social (COLINS), grupo de pesquisa responsável por esta iniciativa. A cidade tem população de 18.050 habitantes (IBGE 2019), distribuídos em 631 domicílios (IBGE 2010), sendo esta a representatividade da pesquisa: pouco mais de 3\% dos domicílios, aparentemente baixa, mas esta pesquisa é considerada inicial para a calibragem do público, dos instrumentos e das questões a serem respondidas, havendo necessidade de desdobramentos e ampliação da mesma. A cidade está situada na região costeira atlântica do Estado do Pará (Figura 1), na confluência do rio Mojuim (referenciado também como rio Bareto) com o rio Pará, em zona estuarina, dedicada principalmente à economia do pescado (peixes e caranguejos), com participação também de prestação de serviços comerciais e públicos, além do turismo ocasional de pesca esportiva.

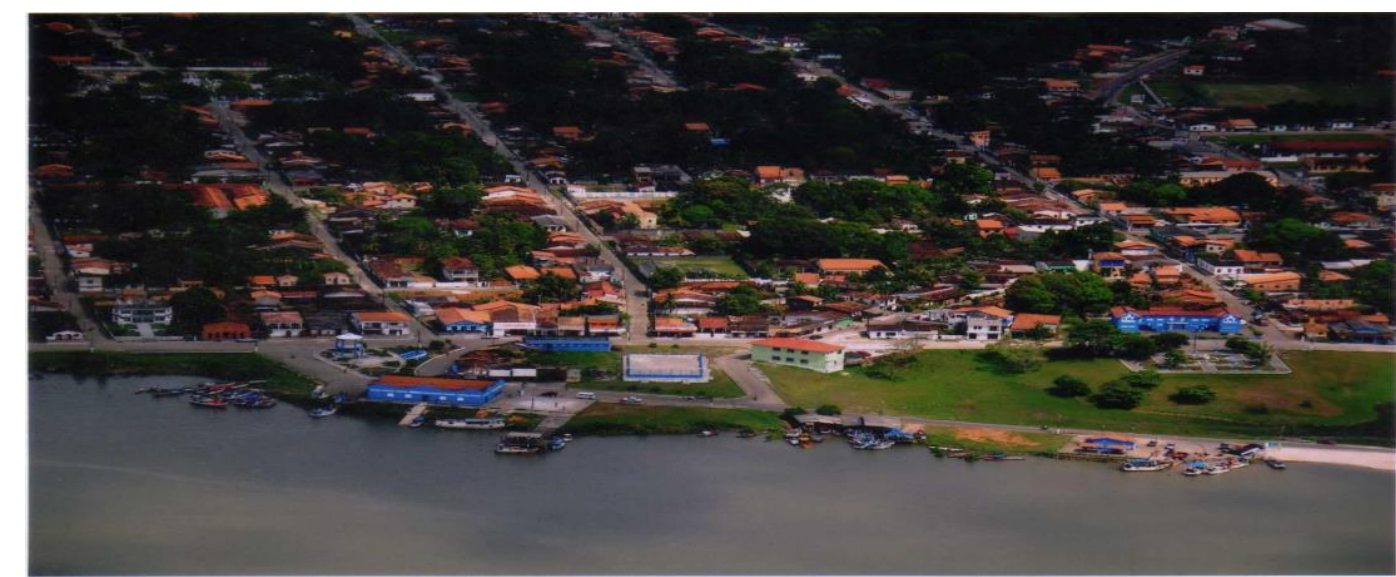

Figura 1 - Vista aérea de São Caetano de Odivelas, em primeiro plano o rio Mojuim Pará, Amazônia

O procedimento metodológico inicial foi a observação participante, relativa ao levantamento da realidade local frente aos efeitos do isolamento social na comunidade. A partir desta observação, pode-se identificar possíveis participantes-modelo da pesquisa, convidando-se aqueles que teriam interesse espontâneo em opinar sobre as afirmativas postas, desde que caracterizados conforme os aspectos de diversidade de gênero, idade, ocupação, formação.

Os participantes da pesquisa têm faixa etária entre 21 e 70 anos, sendo 8 mulheres e 12 homens. Suas atividades são: aposentados (5), professores (2), 
Rev. Interd. em Cult. e Soc. (RICS), São Luís, v. 6, n. 2, p. 227-247, jul./dez. 2020

comerciantes/microempreendedores (3), atividades domésticas (1), autônomos sem especificação (2), pescadores (3), estudantes (2), desempregado (1) e servidor público (1); estas ocupações foram indicadas pelos próprios participantes, escolhidos aleatoriamente conforme interesse em participar da pesquisa.

O instrumento de coleta (Tabela 1) foi do tipo formulário, com 10 afirmativas, aplicado por três universitários, sendo um mestrando, do Programa de Pós-Graduação em estudos Antrópicos na Amazônia (PPGEAA/UFPA), e duas graduandas do Curso de Letras do Núcleo Universitário de São Caetano de Odivelas Prof. Mário Chagas Fernandes (NUSC/UFPA). Cada participante deveria demonstrar sua concordância ou discordância, ou indiferença, na seguinte disposição:

Tabela 1: Formulário investigativo

\begin{tabular}{|c|c|c|}
\hline Número & Pergunta & Opções de Resposta \\
\hline 1 & O isolamento social deve ser obedecido rigorosamente & \multirow{10}{*}{$\begin{array}{l}\text { Concordo Totalmente (4) } \\
\text { Concordo Parcialmente (3) } \\
\text { Discordo Parcialmente (2) } \\
\text { Discordo Totalmente (1) } \\
\text { Indiferente (0) }\end{array}$} \\
\hline 2 & Deve-se evitar o contato físico em casa / na família & \\
\hline 3 & Deve-se evitar contato físico com parentes e vizinhos & \\
\hline 4 & $\begin{array}{l}\text { Deve-se evitar qualquer tipo de reunião (festas, conversas } \\
\text { com outros, jogos, lazer, etc.) }\end{array}$ & \\
\hline 5 & Deve-se evitar sair de casa e da comunidade & \\
\hline 6 & O uso das redes sociais pode substituir os contatos diretos & \\
\hline 7 & $\begin{array}{l}\text { Os meios de comunicação (rádio, TV's, jornais e afins) são } \\
\text { fontes seguras de informação }\end{array}$ & \\
\hline 8 & Os cientistas e a ciência darão a solução à pandemia & \\
\hline 9 & Somente Deus poderá nos salvar da epidemia & \\
\hline 10 & $\begin{array}{l}\text { O uso sem limites dos recursos naturais pelos humanos } \\
\text { provocou a epidemia }\end{array}$ & \\
\hline
\end{tabular}

Fonte: Próprios autores

As afirmativas de 1 a 5 retratam a opinião estrita quanto ao isolamento social, referindo-se à obediência, à restrição, à minimização de contato físico na família e na comunidade e ao trânsito entre a comunidade e o mundo exterior. As afirmativas 6 e 7 referem-se à importância dos meios de comunicação (mídias públicas e sociais) quanto à informação sobre a pandemia e a confiabilidade destas mídias. As afirmativas 8 a 10 referemse ao papel da ciência e da religião a fim de solucionar e/ou dar conforto quanto ao problema da pandemia, sendo que a última afirmativa, considerando essa opinião, trata do papel dos humanos em relação à origem da pandemia.

\section{Resultados da Pesquisa}

O Gráfico 1 apresenta os valores e percentuais resultantes da pesquisa, onde há 3 legendas, a saber: concordância (que engloba total ou parcial), discordância (que engloba total ou parcial) ou indiferença, relativos a cada afirmação do formulário aplicado. 


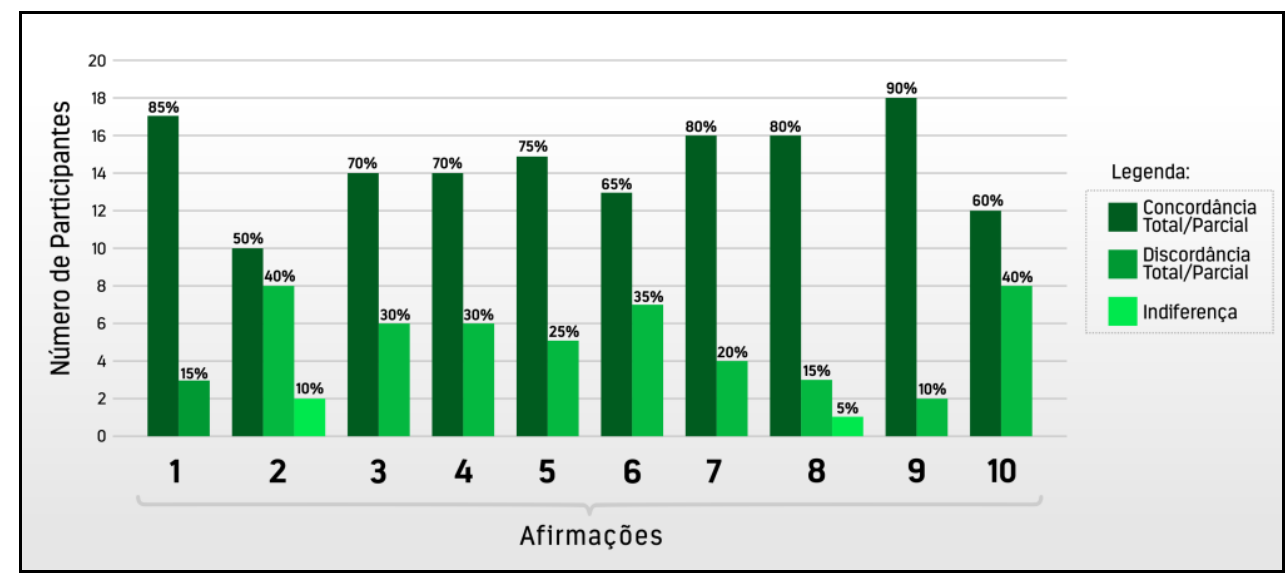

Gráfico 1: Isolamento Social

De forma geral, é possível detectar que houve CONCORDÂNCIA em grande maioria das afirmações, em percentual nunca inferior a 50\% dos participantes, o que demonstra que há aceitação, na maioria das vezes, quanto às afirmativas formuladas pela equipe de pesquisa; as DISCORDÂNCIAS não foram maiores que $40 \%$, mantendo-se abaixo da mediana; e as INDIFERENÇAS foram estatisticamente insignificantes, ocorrendo em apenas duas afirmações e em percentual que não ultrapassou 10\%. O que podemos concluir, de forma holística, que houve grande interesse, por parte dos pesquisados, em se manifestar quanto ao isolamento social, por ser este um tema de grande repercussão no momento, e os participantes não poderiam ficar indiferentes, por isso o ínfimo percentual de quem optou por esta condição.

Em leitura mais amiúde deve-se relativizar, no entanto, essa maioria de concordâncias.

A Afirmativa 1 - $O$ isolamento social deve ser obedecido rigorosamente revela que 8 participantes concordaram parcialmente contra 9 concordâncias totais, e 3 participantes demonstraram discordância parcial. Neste caso, por mais que haja ampla concordância quanto à necessidade de se permanecer em domicílio, para evitar a transmissão, considerando a dúvida quanto à validade desse isolamento chega-se à conclusão que 11 participantes (55\%), 8 concordâncias parciais e 3 discordâncias parciais, têm opinião de não aceitar peremptoriamente o que preconiza as normas de Estado, o que pode abrir margens para o questionamento da validade.

\section{A Afirmativa 2 - Deve-se evitar o contato físico em casa / na família e a} Afirmativa 3 - Deve-se evitar contato físico com parentes e vizinhos são relativas à prática do isolamento, quando os participantes foram instados a opinar sobre a necessidade de nãocontato direto com pessoas de seu entorno, as mais próximas, como pais e filhos, ou parentes e agregados que moram no mesmo domicílio; ou as pessoas de convívio diário, mas que 
Rev. Interd. em Cult. e Soc. (RICS), São Luís, v. 6, n. 2, p. 227-247, jul./dez. 2020

ISSN eletrônico: 2447-6498

habitam outro domicílio como demais parentes e vizinhos. Aqui, no caso de habitarem o mesmo domicílio houve empate técnico entre os que concordam parcialmente (10 pessoas) e os que discordam (8 pessoas, sendo 4 pessoas parcialmente e 4 pessoas totalmente), além de haver 2 pessoas indiferentes. Podemos constatar que, mesmo que seja uma orientação sanitária legal, por ocasião de contaminados no domicílio, não há concordância total para a efetivação desse isolamento em família. Quanto à afirmativa 3, há mais aceitação da afirmativa, mesmo que a concordância total corresponda a 5 pessoas e a concordância parcial a 9 pessoas; há ainda 6 discordâncias, sendo 5 parciais e 1 total, números que são próximos aos da Afirmativa 4 - Deve-se evitar qualquer tipo de reunião (festas, conversas com outros, jogos, lazer, etc.), mas com pequena variação: neste caso da afirmativa 4 , também houve 14 concordâncias, mas com 11 concordâncias totais e 3 concordâncias parciais, o que é menos aceitável reuniões festivas, com maior número de participantes e que estes não sejam obrigatoriamente do entorno da família do participante ou de seu domicílio. Ainda relativo a esta afirmativa houve 5 discordâncias parciais e 1 discordância total.

A Afirmativa 5 - Deve-se evitar sair de casa e da comunidade apresentou 4 concordâncias totais, 11 concordâncias parciais, 4 discordâncias parciais e 1 discordância total. O que verificamos aqui é que o fluxo na comunidade, internamente e externamente, a classifica mais efetivamente como comunidade tradicional em cidade local, pois o que nos leva a crer que existe necessidade de trânsito frequente para o estabelecimento de trocas entre a comunidade e o mundo exterior, talvez em razão de que a comunidade não se autossustenta em sua sobrevivência, ou que "estar com o outro" é uma lógica de afeto e identidade comunitárias, corroborando Diegues (2002) quando caracteriza esse grupo tendo vínculo intergeracional e territorial arraigado, com importância ao núcleo familiar, doméstico e comunal, e ainda pertencer a uma cultura distinta.

As Afirmativas 6 - $O$ uso das redes sociais pode substituir os contatos diretos e 7 Os meios de comunicação (rádio, TVs, jornais e afins) são fontes seguras de informação, relativas ao papel das mídias (mídias sociais ou mídias abertas) durante a Pandemia, apresentaram sutil diferença. Quando instados a se manifestarem sobre as mídias sociais (WhatsApp, Instagram, Facebook, Twitter, e afins) de Internet, os participantes revelaram-se mais de acordo com o fato destas serem substitutivos do contato direto nas relações diárias: houve 8 concordâncias totais e 5 concordâncias parciais, além de 3 discordâncias parciais e 4 discordâncias totais; pode-se entender que este suporte de comunicação já adentrou na vida dos comunitários e que já está "naturalizado" em sua lógica de comunicação. 
De certa maneira as mídias abertas ainda têm um papel relevante na prestação de informações, mas com ressalvas, uma vez que a concordância total de 6 pessoas e a concordância parcial foi de 10 pessoas, e ainda houve 4 discordâncias parciais; ou seja, existe sutil questionamento sobre a credibilidade das informações das grandes redes de comunicação do país, o que, curiosamente, não existe entre as comunicações de indivíduos ou grupos ideológicos na Internet. Talvez daí a preocupação com as notícias falsas (fakenews), uma vez que as redes sociais são menos postas em descrédito, mesmo que sejam tocadas por pessoas e grupos sem compromisso científico, muitas vezes extremamente ideológicos e fundamentalistas, e sem formação profissional e compromisso ético para com a verdade.

A Afirmativa 8 - Os cientistas e a ciência darão a solução à pandemia merece destaque, uma vez que houve 16 concordâncias totais e 3 concordâncias parciais, além de 1 indiferença. Muito sintomático em um momento em que, para além do conforto espiritual em discursos, por vezes negacionistas, de religiosos, a ciência vem assumindo papel de relevância para a descoberta de cura e prevenção à Covid-19. De todo modo, a Afirmativa 9 - Somente Deus poderá nos salvar da epidemia ainda supera em concordâncias totais, pois 18 pessoas afirmaram a salvação divina para este momento de dúvidas e questionamentos, e somente 2 pessoas discordaram (1 parcial e 1 total) que a figura de Deus tem papel fundamental para a reversão da situação. O que nos leva a crer que as duas forças propulsoras de esperanças de futuro melhor são a religião e a ciência, talvez em um apelo que possa unificar essas duas formas de conhecimento da vida humana, mesmo que Deus e a religião se sobressaiam levemente em relação à ciência, e mesmo para esta houve 1 indiferença, ou seja, não há clareza sobre o que os cientistas podem efetivamente fazer para reverter a situação.

Por fim, a Afirmativa 10 - O uso sem limites dos recursos naturais pelos humanos provocou a epidemia demonstra que os participantes não atribuem culpabilidade sobre a doença às ações humanas na natureza, aos efeitos da antropização. Isto porque houve 7 concordâncias totais, 5 concordâncias parciais, 3 discordâncias parciais e 5 discordâncias totais. Entendemos que, mesmo a despeito de haver suspeita da origem do coronavírus na utilização de animais silvestres na alimentação humana, a falta de correlações entre os grupos sociais, seja na China ou em São Caetano de Odivelas, por vezes decorrentes de informação ou formação escolar, fez com que, mesmo em uma comunidade tradicional, que sobrevive principalmente do extrativismo pesqueiro, os principais usuários dessa riqueza natural não consideram que suas atitudes podem comprometer a relação humano e ambiente. Há de se destacar que todos os que discordaram desta afirmação são vinculados, ou já o foram, ao ramo da pesca, como pescadores ou aposentados desta atividade. 
Rev. Interd. em Cult. e Soc. (RICS), São Luís, v. 6, n. 2, p. 227-247, jul./dez. 2020

ISSN eletrônico: 2447-6498

Relativo às afirmações, ou questões propostas, o que podemos depreender, no geral, é que mesmo com a ampla divulgação, nos meios midiáticos abertos, sobre a necessidade do isolamento social, para minimizar-se a cadeia de contaminação, ainda é muito difícil efetiválo em aglomerado populacional de cidades locais, estas consideradas como "as aglomerações (que) deixam de servir às necessidades da atividade primária para servir às necessidades inadiáveis da população, como verdadeira 'especialização do espaço'” (Santos 2008:87), sendo este o caso em São Caetano de Odivelas.

Apesar que haja um conjunto de serviços de atenção à população, próprios da modernidade urbana, como serviços bancários, magazines, supermercados e mercearias, lojas de material de construção e de material de pesca, serviços públicos municipais e estaduais, escolas de educação básica, núcleo universitário, ocorre, de outro modo, como atividade polarizante, a pesca, o que classifica a cidade como de subsistência, com acentuada prática laboral vinculada à comunidade tradicional, em que as relações de proximidade entre os indivíduos (relações de parentesco e compadrio), próprias destas estruturas sociais, criam resistência à aceitação irrestrita de determinações externas e oriundas de um poder estatal, que não participa rotineiramente da realidade local, bem como situam essas determinações em realidade bem distante, e quase estranha, ao meio imediato dos participantes da pesquisa.

O que podemos observar é que a cidade aceita as diretrizes de um governo central e estatal, mas com ressalvas para que o sentido de tradição das relações parentais e comunitárias não se perca, por isso considerar-se que a ciência poderá dar solução à pandemia, mas não sem antes considerar-se Deus como a entidade primeira que poderá nos salvar dessa situação: aqui ciência e religião não são contrárias, mas complementares na compreensão de solução para a covid-19, o que corrobora Diegues (2002) quando este discrimina como uma das características de culturas e sociedades tradicionais, qual seja a importância das simbologias, mitos e rituais para elucidar ou confortar os problemas do cotidiano.

O mesmo serve na compreensão de que os meios comunicativos midiáticos colaboram para a ampliação do conhecimento sobre a pandemia, e também são mecanismos que facilitam a aproximação entre as pessoas, por mais que a própria comunidade não tenha clareza de que suas atitudes humanas podem concorrer para o agravamento da situação quando não se respeita os limites de esgotamento naturais: inexiste a compreensão das correlações entre o local e o global quanto aos efeitos de exploração dos recursos, assim como é distante a percepção de que, algumas vezes, as práticas locais de subsistência e as relações sociais concorrem para o agravamento de problemas advindos das relações antrópicas. 


\section{DISCUSSÃO}

Espera-se, com esta pesquisa, apontar o posicionamento, mesmo que considerando apenas uma localidade, de uma população de cidade local, de porte populacional pequeno, mas representativo, face à pandemia de Covid-19 e face às orientações do governo central quanto à minimização dos impactos deste fenômeno, baseadas nas orientações da ciência, atentando-se para as nuances de práticas culturais e de organização das relações sociais tradicionais como concorrentes às orientações da modernidade médica.

A OMS discriminou como critérios para a suspensão do isolamento social e quarentena, aos países, indicadores, conforme Figura 2.

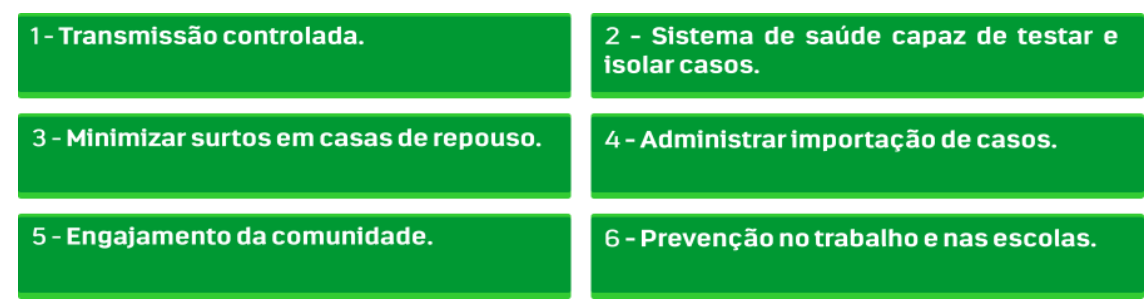

Figura 2 - Indicadores para suspensão do isolamento social (OMS).

A partir dos dados levantados pode-se afirmar que, considerando-se a realidade de São Caetano de Odivelas, as orientações 1, 2 e 4 podem ser alcançadas partindo-se do controle e atenção às demandas econômicas, ecológicas, socioculturais e de segurança social decorrentes de movimentos populacionais (endógenos ou exógenos) no território municipal, a fim de garantir o bem-estar e a boa convivência comunitárias, por mais que inexista, como em todo o Brasil, um sistema de saúde capaz de testar amplamente a população; no máximo, isolar os caso quando estes forem manifestos. O controle e o isolamento de casos poderão ocorrer, mais satisfatoriamente, mediante barreiras sanitárias, fazendárias e de assistência social nos principais acessos ao município e nas principais vias de comunicação interna, com coleta de dados dos transeuntes e controle de fluxos de munícipes e de estrangeiros. De posse da sistematização das informações acerca dos fluxos, poder-se-á antever demandas e indicar soluções prévias a problemas decorrentes, não somente as endemias, mas também o tráfico de drogas, os foragidos de justiça, as fugas de delinquentes, a evasão de impostos, os fluxos de mercadorias e serviços, os trânsitos culturais entre comunidades.

As orientações 5 e 6 podem ser alcançadas mediante a gestão da informação nas comunidades do município, mediante a operacionalização de ações de atenção e controle de fluxos e demandas locais, fornecendo-se instrumentos e meios aos comunitários para atuarem em seus territórios com o registro de fenômenos autóctones e alóctones em meios digitais e 
Rev. Interd. em Cult. e Soc. (RICS), São Luís, v. 6, n. 2, p. 227-247, jul./dez. 2020 ISSN eletrônico: 2447-6498

telecomunicativos, daí ser importante a existência de rede digital de qualidade bem como instrumentos (celulares, tablets, telefonia urbana e rural, radiocomunicação, máquinas fotográficas e de filmagens, etc.), assim como a formação para a pesquisa e o registro desses fenômenos, e ainda a existência de banco de dados a ser constituído a partir dessa coleta, para que se possa estabelecer séries históricas. Com esse engajamento da comunidade no controle e gestão de fenômenos poderemos mais facilmente realizar ações preventivas nos espaços laborais e nas escolas. A orientação 3 não se aplica à realidade de São Caetano de Odivelas.

As observações, até aqui levantadas, direcionam para possíveis orientações às políticas públicas no município de São Caetano de Odivelas, ou municípios correlatos, conforme apontadas na Figura 3.

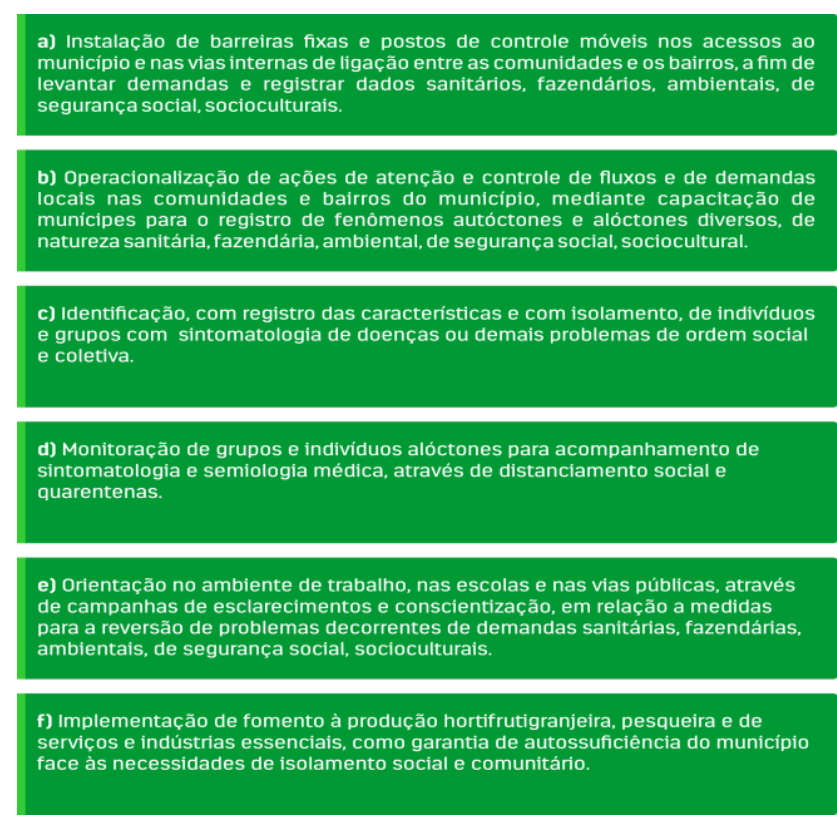

Figura 3: Orientações a serem seguidas (Fonte: Próprios autores)

Com a instauração destas orientações da Figura 3, será possível, a partir dos dados coletados nos espaços de monitoramento dos fluxos, vislumbrar algumas diretrizes para indicadores de isolamento social e/ou seu relaxamento, que não considerem estritamente os impactos diretos da doença - número de infectados, número de mortos, número de curados, leitos hospitalares disponíveis, quantidade de testes por número de habitantes - ou os efeitos da paralisação social na economia - número de desempregados, queda do PIB, queda do poder de compra, inadimplência, falências de empresas. Para essa parcela da população brasileira das chamadas cidades locais, ou de subsistência, o que deve ser mensurado é a capacidade de se manterem como tais, sem prejuízo da sua de sua população. Em vista disso, prevalentemente o conceito a ser utilizado como implementador de diretrizes seja o que 
distanciamento social, que preserva os contatos frequentes entre os comunitários, mesmo que haja resguardo nas situações de contatos cotidianos.

Daí se relevar possíveis indicadores para o distanciamento social, por haver validade em sua aplicação conforme a realidade estudada, que poderão ser baseados na caracterização de uma comunidade tradicional, em cidade local, conforme apresentado na Tabela 2.

Tabela 2: Indicadores de Distanciamento Social

\begin{tabular}{|c|c|c|}
\hline $\begin{array}{l}\text { CARACTERÍSTICA } \\
\text { COMUNITÁRIA }\end{array}$ & $\begin{array}{c}\text { IMPACTO ESPERADO } \\
\text { SEGUNDO DIRETRIZES DA } \\
\text { OMS }\end{array}$ & PROPOSTA DE INDICADORES \\
\hline $\begin{array}{l}\text { 1. Dependência dos ciclos } \\
\text { naturais para a } \\
\text { subsistência. }\end{array}$ & $\begin{array}{l}\text { - Engajamento da comunidade. } \\
\text { - Testagem e isolamento de casos } \\
\text { no segmento agro-extrativista da } \\
\text { comunidade. }\end{array}$ & $\begin{array}{l}\text { - Peso e volume de circulação de produtos } \\
\text { agro-extrativistas do oriundos do município } \\
\mathrm{e} \text { destinados ao consumo interno e à } \\
\text { exportação. } \\
\text { - Quantidade de serviços públicos e } \\
\text { quantidade de servidores de variadas esferas. }\end{array}$ \\
\hline $\begin{array}{l}\text { 2. Noção de território para } \\
\text { a reprodução econômica e } \\
\text { social. }\end{array}$ & $\begin{array}{l}\text { - Prevenção e conscientização em } \\
\text { espaços públicos. }\end{array}$ & $\begin{array}{l}\text { - Taxa de compras no comércio local, pelos } \\
\text { moradores da cidade. } \\
\text { - Meios de comunicação comunitária } \\
\text { (analógicos e digitais). }\end{array}$ \\
\hline $\begin{array}{l}\text { 3. Moradia e ocupação do } \\
\text { território. }\end{array}$ & - Transmissão controlada. & $\begin{array}{l}\text { - Cobertura espacial ( quantidade de pessoas } \\
\text { por } \mathrm{m}^{2} \text { ) nos lugares públicos mais } \\
\text { movimentados no município. } \\
\text { - Densidade demográfica do município. }\end{array}$ \\
\hline $\begin{array}{l}\text { 4. Importância da unidade } \\
\text { familiar, doméstica e } \\
\text { comunal. }\end{array}$ & $\begin{array}{l}\text { - Administração da importação de } \\
\text { casos. }\end{array}$ & $\begin{array}{l}\text { - Quantidade de moradias na cidade / } \\
\text { município. } \\
\text { - Média de pessoas por moradia. } \\
\text { - Percentual de membros por moradia que se } \\
\text { ausentam diariamente para atividades de } \\
\text { sobrevivência (provimento de alimentação e } \\
\text { saúde), internamente ou externamente ao } \\
\text { município. }\end{array}$ \\
\hline
\end{tabular}

Fonte: Próprios Autores

O que propomos com estes indicadores apresentados na Tabela 2 é a atenção às características, mesmo que parciais, de comunidades tradicionais, a fim de que sejam determinadas as diretrizes sem serem atitudes agressivas às práticas locais. Por isso, na primeira coluna à esquerda estão postas essas características, seguidas de orientações da OMS para o relaxamento do isolamento e efetivação do distanciamento sociais e por fim, na última coluna à direita, o que deve ser observado nas cidades locais como regulador para a manutenção ou suspensão das medidas preconizadas tanto pela OMS quanto pelo governo federal e estadual, via suas entidades de saúde pública. 
Rev. Interd. em Cult. e Soc. (RICS), São Luís, v. 6, n. 2, p. 227-247, jul./dez. 2020

ISSN eletrônico: 2447-6498

Entendemos mesmo que seja necessário o lockdown ${ }^{5}$, em primeiro momento, para o levantamento de casos, num cenário em que não há testes para a verificação de contaminação da população. Mas esta seria uma medida inicial, para impedir o ingresso de estranhos à comunidade durante o período curto de verificação das condições sanitárias e de saúde. Depois a gradual abertura, considerando-se estes indicadores de distanciamento social.

\section{CONCLUSÃO}

Podemos afirmar que a pesquisa, mesmo a despeito de um recorte de informantes, pode corroborar a hipótese de que políticas públicas nacionais nem sempre são aceitas e seguidas por populações locais, em decorrência de que existe um hiato entre padrões e modelos universalizantes e as práticas e valores locais. Por isso, merecem uma adequação em conformidade com as cidades locais, em nosso caso, implicando em reconhecimento de formas de antropização distintas, que considerem os grupos locais a partir de suas maneiras de estabelecer e manter seu território, em regime de propriedade, vínculos afetivos, história de ocupação na memória coletiva, uso social e formas de defesa; neste momento, estes aspectos são concretizados na autonomia dos locais em usar e se movimentar em seu território ancestral, com impedimentos pelo isolamento social. Daí que como conceito mais adequado ao reconhecimento dessas particularidades seja a implementação de indicadores de distanciamentos social, com suas respectivas diretrizes de implementação, o que vem a ser nossa contribuição para o momento.

Este trabalho de pesquisa merece ter seus desdobramentos, uma vez que demonstrou ter validade para medir o fenômeno, pretendendo ter ampla aplicação, pois a amostragem representa apenas um local e suas peculiaridades, entretanto, o modelo proposto valida futuras aplicações para aperfeiçoamento dos métodos e das análises. Assim, pode-se complementar o estudo com a geração de índices, a partir dos indicadores propostos, com formulação mais objetiva de indicadores de distanciamento, isolamento ou relaxamento das medidas, tendo em vista moradias, densidade demográfica, atividades essenciais para a sobrevivência (saúde e alimentação, disponibilidade de EPI, ameaças ao equilíbrio ambiental). Entendemos ainda que é urgente essa ampliação, pois os efeitos do isolamento taxativo, para uma população local mais ainda, implicam em prejuízos psicológicos e de sociabilidade.

\footnotetext{
${ }^{5}$ Protocolo de emergência que se destina a restringir a mobilidade de pessoas, que deve ser iniciado por alguma pessoa em condição de autoridade.
} 
Evidentemente que a pesquisa realizada poderá apontar mais variantes e direcionamentos a partir dos dados coletados, além de ser necessária a ampliação da coleta de dados, mas por ora nosso objetivo de criação de um modelo para apontar a opinião e a concordância/discordância dos comunitários e indicar possíveis soluções para os impasses na limitação de mobilidade dos locais, bem como orientações futuras para as políticas públicas municipais, foi atendido a contento.

Por fim, intentamos, com este trabalho, compreender que a nação se forma desde categorias de parentesco e religião, como já destacado por Anderson (1993), sendo uma comunidade política imaginada, "porque aun los miembros de la nación más pequeña no conocerán jamás a la mayoría de sus compatriotas, no los verán ni oirán siquiera hablar de ellos, pero en la mente de cada uno vive la imagen de su comunión" (ANDERSON,1993,p.23). E a comunhão nesse momento entre uma cidade local da Amazônia e o regramento da nação brasileira se dá exatamente por nos imaginarmos comungando de um mesmo fato, que tristemente é uma Pandemia.

\section{REFERÊNCIAS}

ANDERSEN, K.G., RAMBAUT, A., LIPKIN, W.I. et al. 2020. The proximal origin of SARS-CoV-2. Nat Med 26:450-452.

ANDERSON, B. 1993. Comunidades imaginadas. México: FCE.

BOLLMAN, H. A. 2021. "Metodologia para avaliação ambiental integrada". In Indicadores ambientais: conceitos e aplicações. São Paulo: EDUC/COMPED/INEP.

BRASIL, Lei 13979/2020 - Dispõe sobre as medidas para enfrentamento da emergência de saúde pública de importância internacional decorrente do coronavírus responsável pelo surto de 2019. Disponível em: http://www.planalto.gov.br/ccivil_03/_ato20192022/2020/lei/L13979.htm. Acesso em 30/04/2020.

DIEGUES, A. C. 2002. O mito moderno da natureza intocada. 4.ed. São Paulo: Annablume: Hucitec.

FERNANDES, J. G. SANTOS, FERNANDES, D. SANTOS. Personas e habitus: estudo de perfis antrópicos na Amazônia oriental. Espaço Ameríndio, Porto Alegre, v. 12, n. 1, p. 81111, jan./jun. 2018.

BRISCESE, G., LACETERA, N., MACIS, M. E TONIN, M. Compliance with COVID-19 Social-Distancing Measures in Italy: The Role of Expectations and Duration. 2020. NBER WORKING PAPER SERIES. DOI: 10.3386/w26916.

IBGE. Instituto Brasileiro de Geografia e Estatística. Disponível em www.ibge.gov.br. Acessado em 20 de Abril de 2020. 
Rev. Interd. em Cult. e Soc. (RICS), São Luís, v. 6, n. 2, p. 227-247, jul./dez. 2020 ISSN eletrônico: $2447-6498$

JN, 2020. Governo de SP usa dados de celulares para localizar aglomerações. Disponível em https://g1.globo.com/jornal-nacional/noticia/2020/04/08/governo-de-sp-usa-dados-decelulares-para-localizar-aglomeracoes.ghtml. Acessado em 27/abril/2020.

JOHNSON, A. G. 1997. Dicionário de sociologia. Rio de Janeiro: Jorge Zahar Editores.

LIFANG Li, Qingpeng Zhang, Xiao Wang, Jun Zhang, Tao Wang, Tian-Lu Gao, Wei Duan, Kelvin K et al. 2020. Characterizing the Propagation of Situational Information in Social Media During COVID-19 Epidemic: A Case Study on Weibo. IEEE Transactions on Computational Social Systems. DOI: 10.1109/TCSS.2020.2980007.

OMS/Organização Mundial de Saúde. OMS divulga lista de critérios para suspender o isolamento social. Disponível em: https://www.tecmundo.com.br/ciencia/152029-omsdivulga-lista-criterios-suspender-isolamento-social.htm. Acessado em: 30/04/2020.

OPAS/Organização Pan-Americana da Saúde. OMS afirma que COVID-19 é agora caracterizada como pandemia. https://www.paho.org/bra. Acessado em: 30/04/2020.

SANTOS, M. 2008. Da totalidade ao lugar. São Paulo: EDUSP.

SPI. Social Progress Index. Disponível em https://www.socialprogress.org. Acessado em 20 de Abril de 2020.

UFRGS/Universidade Federal do Rio Grande do Sul - Telessaúde. Qual a diferença de distanciamento social, isolamento e quarentena?. Disponível em:

https://www.ufrgs.br/telessauders/posts_coronavirus/qual-a-diferenca-de-distanciamentosocial-isolamento-e-quarentena/. Acessado em: 30/04/2020.

WANG, H., WANG, Z., DONG, Y. et al. 2020. Phase-adjusted estimation of the number of Coronavirus Disease 2019 cases in Wuhan, China. Cell Discov 6:10. DOI: https://doi.org/10.1038/s41421-020-0148-0.

YAN BAI, MD1; LINGSHENG YAO, MD2; TAO WEI, MD3; et al. 2020. Presumed Asymptomatic Carrier Transmission of COVID-19. Jama Network. DOI: 10.1001/jama.2020.2565. 